\section{THE CHARACTERS OF THE BACILLUS COLI AS AN INDICATOR OF EX- CRETAL CONTAMINATION.}

By WILLIAM G. SAVAGE, M.D., B.Sc. LoND.,

MEDICAL OFFICER OF HFALTH OF COLCHESTER: LATE LECTURER ON BACTERIOLOGY AT UNIVERSITY COLLEGE, CARDIFF.

THE fundamental importance of this organism as a test for excretal contamination need not be insisted upon here; it is fairly generally recognised. Also most observers are in accord as to what are the essential characters of a quite typical bacillus coli. The main point which is still unsettled is how far can an organism deviate from this typical bacillas coli communis and still have an equal significance as a test for excretal contamination. This is a very important practical question. At present much confusion prevails and the bacillus coli of one observer would not be accepted by another as an organism of equal significance. In giving the results of investigations with this organism it is usually advisable to specify exactly what is meant and to indicate all the tests employed and the results obtained. On the other hand, although a multiplicity of tests may make for increased accuracy, yet it is desirable in the interests of routine work to have a minimum number of tests which can be made and yet which will be sufficient to determine accurately whether or no any given organism can be classed as a bacillus coli, an indicator of frcal contamination. It is from this point of view that this paper is written. The various characteristics generally employed will now be considered, only the ones in dispute being discussed in detail.

Morphology and tinctorial characters.-All observers agree that this organism is a short kacillus with rounded ends and showing no spores. It stains readily with ordinary aniline dyes but is decoloured by Gram's method of staining.

Motility.-The typical bacillus coli communis is described as a motile organism. Is it essential that each organism isolated should exhibit motility and if it does not are we to reject it as not being a true bacillus coli?

My experience of motility is that its exhibition by different races of bacillus coli is very variable. Among organisms otherwise giving in every respect all the characters of the typical bacillus coli some will be found to be sluggishly motile, some very actively motile, others exhibiting no motility at all. 'I'he methods used to examine for motility were either, or both, of the following: examination in hanging-drop preparation of a not greater than 24 hours' old broth culture or examination of young gelatin-slope cultures (after less than 24 hours' incubation at from $20^{\circ}$ to $22^{\circ} \mathrm{C}$.) in a hanging drop of sterile broth. Occasionally an organism non-motile by one method would be distinctly motile by the other. How far is this motility or non-motility a stable character and how far is it a question of environment? Gilbert and Lion divided the varieties of bacillus coli found in the stools of 60 healthy men into two groups: (1) motile and (2) non-motile. Other observers describe their results as variable.

Motility is a fundamental character and too important to be used as a mere variety differentiator. It must, I think, be accepted that all true bacilli coli are motile. The extiibition of motility is, on the other hand, largely a question of environment. If this is so the apparently non-motile bacilli coli should all be made to exhibit motility under suitable environment. I have made a considerable number of experiments in this direction from time to time and have in almost all cases been able definitely to show true motility in organisms otherwise quite typical but, when isolated. nonmotile, sometimes by prolonged growth on artificial media, at others by varying the method of examination. My conclusions are that all true bacilli coli are motile but that when isolated many of them do not exhibit any motility. These on prolonged subcultivation or other appropriate means can usually be made to show motility. From this it follows that as a practical test for the diagnosis of this organism the presence of motility when isolated is of little or no value.

Liquefaction of gelatin.-It is usually accepted that the true bacillus coli does not liquefy gelatin, although some observers have described liquefying forms as members of this group. All liquefiers of gelatin should be excluded as not true organisms in my opinion. The cultivations should be kept in the incubator for at least two weeks.

Gelatin slope growth.-Rapid growth should take place at from $20^{\circ}$ to $22^{\circ} \mathrm{C}$., visible within 24 hours, and yielding within 48 hours a bluish, smooth, translucent growth which remains unaltered after two weeks' incubation. Slight variations are sometimes met with, the growth being in some races thicker and whiter than the typical bluish translucent variety. The variations in my experience are but slight and this is a most valuable culture test.

Gelatin surface colonies.-My experience of gelatin surface colonies is that while the majority are perfectly typical there are other types which are not uncommon and which are given by organisms typical in all other respects. The typical colonies are well developed after from 40 to 48 hours in the cool incubator, and under a low power of the microscope appear as flat colourless or pale brown colonies with an irregular outline and wavy indented margin. Over the surface and extending in from the margin, and particularly observable away from the centre, are a number of wavy lines (marmoration). Sometimes the colonies are uniformly granular and without these lines.

Next most frequently met with after the above (type A) is what $I$ have called type $B$. These colonies are to the naked eye somewhat raised and circular, while they are whiter and more opaque than type $A$ and generally somewhat smaller. Under a low power they appear as welldefined colonies, nearly circular, and with well-defined slightly wavy borders. They are brown, uniformly and finely granular all over, and without wavy lines. The colonies from bacillus coli when growing in unfavourable circumstances are sometimes still smaller and perfectly circular, with quite smooth well-defined margins. Under a low power they are brown and uniformly granular (type C). A small number of colonies of this bacillus are when isolated quite abnormal. These characters are independent of whether the organism is perfectlv typical in other ways or slightly removed from the typical. ${ }^{1}$

These variations in the types of the colonies are mainly no doubt due to immediate environment, but also partly to acquired characters and the influence of more remote environment. As a rule, an organism giving atypical colonies can be induced by artificial cultivation subsequently to exhibit typical colonies. For practical purposes it will be found that frequently, indeed usually, the colonies are almost or quite typical particularly when the organism has been isolated from drinking water, yet the fact that they are not typical does not exclude them of necessity from being true bacilli coli

Agar slope.-This is an abundant rapid growth but of no diagnostic significance. The uniform turbidity produced in broth is also of no diagnostic significance since it is given by so many organisms.

Indol production.- This is one of the classical characters of the bacillus coli. It may be shown in broth (sugar free) but is most reliably demonstrated in peptone-water cultures

TABLE I.

\begin{tabular}{|c|c|c|c|c|}
\hline Source. & $\begin{array}{c}\text { Number } \\
\text { of } \\
\text { bacillus } \\
\text { coli ex- } \\
\text { amined. }\end{array}$ & $\begin{array}{c}\text { Indol } \\
\text { pro- } \\
\text { duced. }\end{array}$ & $\begin{array}{c}\text { No } \\
\text { indol } \\
\text { pro- } \\
\text { duced. }\end{array}$ & $\begin{array}{c}\text { Per- } \\
\text { centage } \\
\text { giving } \\
\text { indol re- } \\
\text { action. }\end{array}$ \\
\hline $\begin{array}{lllll}\text { Water-supplies } & \ldots & \ldots & \ldots & \ldots\end{array}$ & 135 & 127 & 8 & 94 \\
\hline Human excreta (healthỵ) ... ... & 19 & 18 & 1 & 95 \\
\hline 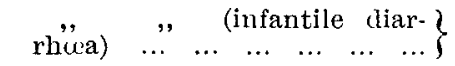 & 10 & 10 & 0 & 100 \\
\hline $\begin{array}{lllll}\text { Animal excreta } & \ldots & \ldots & \ldots & \ldots\end{array}$ & 18 & 14 & 4 & 78 \\
\hline $\begin{array}{lllllll}\text { Sewage } & \ldots & \ldots & \ldots & \ldots & . . & \ldots\end{array}$ & 5 & 5 & 0 & 100 \\
\hline $\begin{array}{llllllll}\text { Soil } & \ldots & \ldots & \ldots & \ldots & \ldots & \ldots & \ldots\end{array}$ & 12 & 12 & 0 & 100 \\
\hline $\begin{array}{lllll}\text { Tidal river mud } & \ldots & \ldots & \ldots & \ldots\end{array}$ & 38 & 34 & 4 & 89 \\
\hline Sea water and tidal river water & 13 & 13 & 0 & 100 \\
\hline 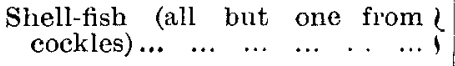 & 22 & 16 & 6 & 73 \\
\hline $\begin{array}{llllllll}\text { Flies } & \ldots & \ldots & \ldots & \ldots & \ldots & \ldots & \ldots\end{array}$ & 18 & 17 & 1 & 94 \\
\hline $\begin{array}{llllll}\text { Totals... } & \ldots & \ldots & \ldots & \ldots & \ldots\end{array}$ & 290 & 266 & 27 & $91 \cdot 7$ \\
\hline
\end{tabular}

1 For further details sec paper by ths write: in the Journal of Pathology and Bacteriology, March, 1904. 
(from 7 to 10 days old). Is this an essential character, and is an organism typical in every other way, but which does not produce indol, to be considered not a true bacillus coli communis?

The results of a number of bacilli coli recently worked out by me and isolated from various sources are given as regards indol production in Table $I$. In this table are only enumerated organisms which are typical in their other characters, such as acid production, fermentation of lactose and glucose, coagulation of milk, positive neutral red reaction, typical growth on gelatin slope and without any liquefaction of the medium. The formation of indol was tested for in peptone water (from 7 to 10 days' incubation at $37^{\circ} \mathrm{C}$.) in every case, except for a few of the bacilli coli isolated from drinking waters, which were tested in ordinary broth. In these if a negative result was obtained with broth a further examination was made in peptone water cultivations.

From Table I. it will be seen that $8 \cdot 3$ per cent. of bacillus coli, otherwise typical, gave no indol when isolated. The percentage of negative results varied considerably with the sources of the organisms, being lowest (73 per cent.) for bacillus coli isolated from cockles. Are these 24 organisms, otherwise quite typical, to be rejected from the fold of the elect bacillus coli? It seems to me that the question turns upon the variability of this character.

I have from time to time re-tested a number of the above organisms which, when first isolated, showed no indol production, and in most of them I have been able to demonstrate subsequently true indol production in peptone-water cultivations after one week's growth at $37^{\circ} \mathrm{C}$. In every case the method of indol testing has been to add from 0.5 to 1.0 cubic centimetre of 0.02 per cent, potassium nitrite solution and then six drops of pure sulphuric acid. The tubes were then either left for one hour at room temperatures, or for my later work kept for ten minutes at about $60^{\circ} \mathrm{C}$. in a water bath.

I believe that under unfavourable conditions the power of indol production may be lost, to be subsequently often reacquired if the conditions are more suitable. Many workers, however, do not recognise the possible variability of this character and Horrocks ${ }^{2}$ states: "I have never been able by any treatment whatsoever to cause an organism, which when first isolated from dejecta showed no signs of indol formation, to assume that faculty." The italics are mine. That may well be so for dejecta but I believe that with less favourable environment this property may be lost.

For practical working purposes I would only reject an organism typical in all respects, except that no indol was formed, as not a true bacillus coli when after several weeks' growth in the laboratory and again testing in fresh peptone water it still failed to produce indol. That is, I should reject it as not having the full significance as an indicator of fairly recent excretal contamination which attaches to typical bacilli coli.

Production of acid.-Production of acid in litmus milk or in litmus whey is a constantly present character of bacillus coli communis. The formation of acid must be permanent since some allied organisms (bacillus enteritidis group) are characterised by the formation of alkali after a transient stage of acid production. I think that any organism which does not produce permanent acidity in litmus milk (or whey) should not be considered as a true bacillus coli. Out of many hundreds of bacilli coli isolated I have never found this character variable or absent.

Milk coagulation.-This is rlue in practically all cases to the formation of acid and in my experience commences when 32 per cent. of acid has been produced and is usually complete when about, or rather under, 40 per cent. has been produced. ${ }^{3}$ It usually takes place within three days but the tubes should be incubated for at least two weeks at $37^{\circ} \mathrm{C}$ before being rejected. Is this an essential character? Out of 250 bacilli coli isolated from different sources and which were typical as regards all the ordinary characters of this organism (this does not include gelatin surface colony characters or the possession of motility) only ten failed to coagulate milk. These ten all produced permanent acidity in milk but failed to elot it even when incubated at $37^{\circ} \mathrm{C}$ for as long as one month. Is this a variable characteristic My experience is that it is stable and but very little variable. I have made extended attempts to cause these

2 Jomrnal of the Royal Army Melical Corps, rol. i., No. 5, p. 366. 3 Tor further particulars see article loy the writer on thi
the Journal of Pathology and Bacteriology, Noventher, 1904. non-coagulating bacilli to coagulate milk by artificial means but without success. The methods used included growing in milk containing calcium chloride, soluble phos phates, prolonger artificial incubation in milk, frequent sub cultivations from one milk tube to another, \&c., but none induced clotting. I do not think these experiments need be detailed further.

In a few cases I have found no coagulation in the first milk tube and subsequent clotting when at once reinoculated into fresh milk tubes, but these are not included in the above and were probably due to some peculiarity in the milk media tubes. For practical purposes, in my opinion, organisms which do not coagulate milk within 14 days should not be considered as true bacilli coli. On the other hand, I think it highly probable that these organisms, non-milk coagulators but typical in all other ways, are derived from typical bacilli coli but have lost their power of producing a sufficient quantity of acid to coagulate the milk, presumably from adverse environment. Taking this view, I would provisionally regard them as of less significance than quite typical bacilli coli, since the freal contamination may have been more remote, but if they can be shown to be prevalent in large numbers in excrement and absent, or relatively absent, in unbefouled materials, then, of course, they would have a significance of their own. The origin of these ten organisms does not negative this view, since one was derived from "made soil," one from horse manure, and one from tidal river mud containing at the same time perfectly typical bacillus coli communis, while the remaining seven were from water-supplies in all of which the quite typical organism was isolated from time to time, frequently at the same time. It is noteworthy that out of the large number of different sources of water-supply examined two should have been derived from the same source (one six months later than the other) and two from another source (but with a year's interval). Of course organisms only superficially resembling the bacillus coli but differing in several characters as well as non-coagulation of milk are not infrequently met with but these are not included in the above.

The fermentation of certain carbohydrates must be considered as the most important character of this organism.

Glucose fermentation.-All bacilli coli ferment glucose with production of acid and gas but since this property is shared by a large number of other organisms it is not a very distinctive characteristic.

Lactose fermentation. - This is, perhaps, the most important differentiating character. All true bacilli coli ferment lactose with production of acid and gas. Extended experience has convinced me of its fundamental importance and I would reject all organisms as not true bacillus coli-communis if they did not ferment lactose with production of acid and gas. In this way a number of rather closely allied organisms can be excluded, which no doubt have a significance and importance of their own, but which cannot be classed as having the same significance as typical bacillus coli. In this connexion a number of organisms which $I$ bave isolated from time to time, and which all have the common property that they ferment lactose much less than the typical organism, are of interest. The characters of 12 such organisms fairly recently isolated and from a variety of sources are given in Table II.

All lactose fermentations were tested in Durham tubes in media consisting of 1 per cent. lactose and 1 per cent. peptone in water tinted blue with litmus solution. When the amount of gas produced is mentioned it is to be understood as being the height of the gas in the inner tube. The tubes were of approximately the same diameter but the measurement can only be considered as a very rough one.

Are these organisms to be considered as true bacillus coli? They generally differ in one or other points from the quite typical bacillus coli. Thus No. 1 when first isolated coagulated litmus milk only after ten days incubation at $37^{\circ} \mathrm{C}$. It was also very actively motile. When isolated it produced acid in lactose-peptone solution but only two or three bubbles of gas. After being kept in the laboratory a week or two it produced one-quarter of an inch of gas in the inner tube after three days incubation. Kept from four to five months in the laboratory and again tested in lactose-peptone water it rapidly produced gas-i.e., two-thirds of an inch in two rlays. Also with fresh litmus milk the milk was coagulatel after six days' incubation. No. 2 was typical in ever $y$ way except the slight production of gas in the lactose tube. Re-examined after six months and after rejuvenation 


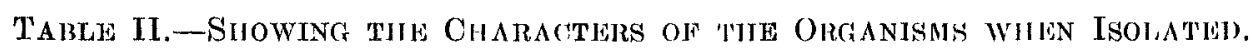

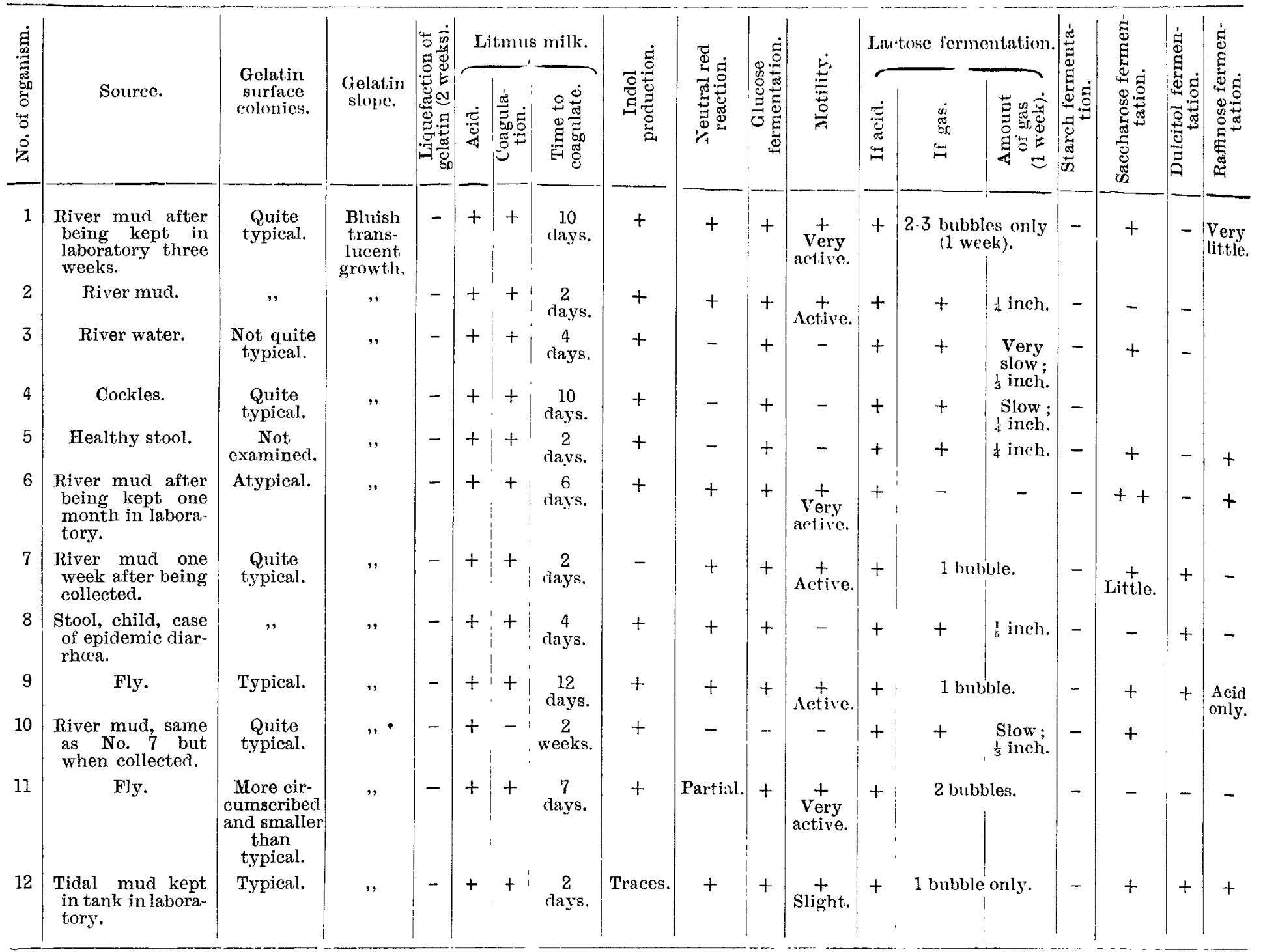

by growing first in broth, then on gelatin plate, then in litmus milk, it gave the same results. Here the slow and little lactose fermentation was constant. In the same way No. 3 when isolated gave no neutral red reaction and the gelatin surface colonies were not perfectly typical. After some months in the laboratory, the gelatin colonies were quite typical but no neutral red reaction as before. The repetition of the lactose fermentation was also very similar in both, yielding after four days' incubation only acid and one bubble of gas, but after six days as much as one inch of gas in the inner tube. For No. 4 apart from slow and slight production of gas in lactose-peptone water, milk was coagulated only on the tenth day (repeated with same result on several occasions) and no neutral red reaction was obtained. It then died out, so that fresh examinations could not be made. No. 5 was very similar except that it clotted milk rapidly. Unlike most bacilli coli it only fermented mannite slowly and not well. It died out so could not be re-examined. No. 6 is included here because at first sight it belongs to this group. It is, I believe, however, quite a different organism and mainly characterised by its fermenting saccharose and mannite with extreme production of gas. Maltose and galactose, as well as glucose, are all rapidly fermented. Repeated growth in fresh lactose-peptone tubes gave always acid, but never more than one bubble of gas. The gelatin surface colonies, examined on several occasions and after long intervals of time, never became typical, being always smaller and less inclined to spread than the common type of bacillus coli. This organism is certainly not a bacillus coli. No. 7 when isolated produced no indol and only gave one bubble of gas in the lactose tube. Re-examined one month later and after being kept on artificial media for that time it gave the same results with the lactose tube and still gave no indol. I hope to re-examine again after some months' growth in the laboratory. No. 8 when isolated fermented lactose with but little production of gas. Reexamined two months after isolation it fermented lactose still slowly but with production of more gas (from one-third to one-half of an inch). No. 9 was re-examined two months after isolation, when one-fifth of an inch of gas was produced in the inner tube of the lactose medium after three days' incubation. When isolated, milk was coagulated in 12 days but two months later in from five to six days. With No. 10 when isolated, milk was not coagulated in two weeks but on inoculation from this into fresh litmus milk tubes gave complete clotting in three days, so this may have been due to some abnormal condition of the first milk tube. Fresh lactose inoculations after six weeks in the laboratory gave now typical and rapid gas production. When ssolated no gas was formed in nentral red glucose agar shake preparation and no neutral red reaction. This was repeated with exactly similar results on several occasions soon after isolation. After six weeks in the laboratory there was fairly abundant gas production in freshly made shake preparations but still no neutral red reaction. The latter was also absent in neutral red broth cultures. After two months on a gelatin slope in the laboratory a complete neutral red reaction was easily obtained with No. 11, but the lactose fermentation was still but slightly marked as regards the production of gas (one-quarter of an inch in five days). No. 12 has not as yet been re-examined, except that the lactose fermentation results have been repeated several times with identical results and as recorded.

These organisms have been described in considerable detail because they, in part at least, illustrate, I believe, the effects of unfavourable environment. Excluding No. 6, I believe that the others are true bacilli coli altered by environment. No less than five were from mud from tidal waters kept for considerable periods in the laboratory. Under laboratory conditions, with abundant nutriment, in most cases some return to the normal was witnessed and with further investigation would probably be still more pronounced. Their practical significance is, however, debateable, since it may be argued that even if they are altered bacilli coli they do not point to recent pollution. They are not infrequently met with but provisionally I do not rely on, or consider, them as indicators of recent pollution, 
Sacoharose fermentation.-All workers are in accord that this cannot be considered an essential character of bacillus coli. Escherich's bacillus coli communis does not ferment saccharose. Some typical bacilli coli, as usually defined, ferment cane sugar; others, probably the majority, clo not. Some further particulars in regard to this and the fermentation of other sugar-like bodies are considered below.

Stareh fermentation. - The true bacillus coli does not ferment starch. Organisms are occasionally met with which resemble the bacillus coli closely but which ferment starch with the production of acid and gas. Apart from their gelatin surface colonies which are usually more compact, they may be suspected by the fact that their gelatin surface growth is thicker and whiter than the typical appearance. They are non-motile. I have isolated such organisms from as little as ${ }_{10000}^{\frac{1}{10}}$ th of a cubic centimetre of sewage, but in my experience the are not abundant in sewage or excreta. I have not tested their growth on potato but, as a practical measure, if an organism gives a whiter and thicker growth on a gelatin slope than the typical appearance, it is advisable to test if it ferments starch (e.g., 1 per cent. starch peptone litmus water). Lactose and glucose are fermented, milk is acidified and coagulated, and indol is produced. Of two such organisms recently isolated one fermented saccharose, the other did not.

In regard to the fermentation of maltose, galactose, lævulose, mannitol, glycerine, \&c., I have not founcl that specially testing for such fermentation has up to the present yielded results worth the trouble or of value in the differentiation of this organism.

Potato.-In my opinion to grow this organism on potato serves no useful purposes, apart from the possible differentiation of a bacillus lactis aerogenes organism, and can be omitted without loss. In the same way the reduction of nitrates to nitrites is caused by bacillus coli, but this property is one common to so many other bacteria that it is valueless as a routine test.

Neutral red reaction. - This is a very useful test but the reaction is one given by a number of other organisms. 1 have found the reaction to be slightly, but only slightly, variable and from time to time have isolated organisms quite typical in all other ways which when isolated gave no neutral red reaction (in glucose neutral-red agar shake preparations) but which after a short period of artificial subcultivation in the laboratory gave the reaction. If no neutral red reaction is obtained usually the organism isolated also deviates in one or other property from the typical bacillus coli.

Pathogenicity.-Nost bacteriologists, at least in this country, have not found that the pathogenicity of isolated bacillus coli is of any help in determining the potency for evil of the material (soil, water, \&c.) under investigation. As a routine test it is not to be commended.

In regard to the different methods for isolating and indicating the presence of bacillus coli such as MacConkey's medium, neutral red, \&c., none of them can be relied upon to indicate by themselves with certainty the presence of bacillus coli. 'They are invaluable as an aid to isolation but in every case the bacterium must be separated in pure culture and its characters worked out. This is apparently accepted by all workers at this subject. While it is of advantage to employ as large a number of tests as possible, yet for routine work, when the labour involved is considerable, it becomes of great practical importance to have a minimum number of tests to use and yet tests which will give a sufficiently reliable means of indicating if any organism is a true bacillus coli or not. 'The work done on the characters of this organism is so large and on some points the unanimity is so considerable that it should not be difficult to fix a minimum number of tests to do and a minimum number of positive results to obtain.

The report of the committee appointed at the 1903 Congress of the Royal Institute of Public Health to consider the standardisation of methods for the bacterioscopic examination of water, issued in July, 1904, ${ }^{3}$ deals with this question and lays down essential characters. These, I believe, would be accepted by most public health bacteriologists as essential, although personally I have found motility is very frequently not exhibited, on isolation, by bacillus coli quite typical in all other respects. Put another way, I believe it would be of great benefit to public health bacteriology if bacteriologists would agree as to the essential subcultivations to perform.

3 See Journal of State Medicine August, 1904.
The six tests of the commiltee, in my opinion, might be even reduced to five, omitting growth on agar slope, and the following would give all the essential tests-i.c., (a) growth on gelatin slope; (b) litmus milk at $37^{\circ} \mathrm{C}$.; (a) lactose-peptone litmus solution (in a Durham tube); (d) peptone water; and (e) glucose neutral red agar shake preparation. Growth in glucose-peptone litmus solution in a Durham tube and another in nentral red broth can be substituted for this. From this the following results should be recorded. 1. Morphology and motility. These can be conveniently investigated from (a) - e.g., a hanging-(lrop preparation in broth after 20 hours' incubation. I do not think it essential to stain by Gram's methorl as a routine practice. 2. 'Translucent non-corrugated appearance on gelatin slope. 3. Non-liquefaction of the gelatin (two weeks). 4. Permanent-i.e., two weeks-acid production in litmus milk. 5. Milk clotting (within two weeks). 6. Lactose fermentation with the production of acid and gas. 7. Glucose fermentation (production of gas in glucose neutral red agar shake preparation). 8. Neutral red reaction; fluorescence and reduction to yellow. 9. Production of indol in (seven to ten days at $37^{\circ} \mathrm{C}$.) peptone water. I believe that these tests are for all practical purposes quite sufficient reliably to indicate the bacilli coli which indicate excretal contamination. They require only five tubes of media and they are quickly performed.

I would suggest the use of the term excretal bacillus coli, and that an organism giving all these characters (whether motile or not) should be definitely implied when the term $e x-$ cretal bacillus coli is used. My experience is that the majority of organisms isolated in routine work as suspected bacillus coli from fluids such as neutral red broth or MacConkey's medium will give characteristic results with all these media. Bacillus-coli-like organisms, however, do not, as every worker at this subject is well aware, always yield all positive results with the above tests, and one or other of them may not be obtained. From the literature of the subject two rather opposite views seem to be held. On the one hand, the advocates of the one view draw the line strictly and say that an organism which does not give all the above, and perhaps other tests also, is not a bacillus coli indicating excretal contamination; on the other hand, others include bacteria lacking one or more of the above-e.g., milk clotting, indol production-and still include as bacillus coli indicating excretal contamination. The first view may, I believe, exclucle organisms which are true indicators of excretal contamination but which have lost one or other of their original characters from unfavourable environment; the latter view is still less satisfactory since it may undoubtedly include organisms found in unpolluted sources and which do not indicate excretal pollution. 'The key to the question appears to turn upon the variability of these characters and from that point of view $I$ have carried out a large number of experiments during the past three years. My personal opinion in the matter is that the following characters should be considered essential: a possible morphology, characteristic appearance on gelatin slope (variable within slight limits), non-liquefaction of gelatin, fermentation of glucose and of lactose, permanent acid production in litmus milk, and coagulation of milk within two weeks. I do not think it matters whether motility is exhibited or not. Indol reaction is a most important test but $I$ do not regard it as so quite essential as the above and should only reject when no indol could be obtained after laboratory subcultivation for some time and then fresh tests made. The neutral red reaction is also of great importance but is not carried out by all workers, so that its precise value cannot be so readily determined.

I am far from implying that organisms which do not give all the above tests (e.g., organisms which fail to clot milk otherwise positive in their characters) are of necessity not indicators of fæcal contamination. They very possibly may be but the position in regard to them is not so sound as for those which I have ventured to call excretal bacilli colimeaning by the term not that they are the only bacilli coli found in excreta, for they are not, but that they are trustworthy indicators of excretal contamination. For this group we ro know that they are abundant in freces and in sewage, and we do know that they are alsent or relatively absent in sources such as water, mud, and soil not recently polluted. The obvious deduction is a strong one. For the less typical they probably have a sionificance of their own but it has not been so accurately gauged and so more care is required in drawing conclusions. I do not believe, however, that such organisms can be passed by as of no significance. 
The main object of this paper has been to indicate the tests which, in my opinion, are the least which should be done but which yield all the evidence necessary to enable us to gauge whether or no the organism found is one not met with in pure sources but found abundantly in contaminated sources and to urge the need for uniformity. ${ }^{4}$

It must not be supposed, however, that all organisms marked off by the above tests are identical even if the differences of gelatin surface colonies, presence or absence of motility, be neglected. If such organisms be further examined to determine their power of fermenting different sugars and allied bodies it will be found that many further divisions can be made. Thus, some will ferment saccharose, others not, some dulcitol (dulcite), others not, \&c.

I have been for some time now engaged in work having for its object the differentiation of bacilli coli from different sources, in particular from human and from animal sources, and for this purpose have made use of different sugars. The details which follow can only be considered as a preliminary note. Dealing only with bacilli coli which exhibit all the characters described above - morphology, characteristic gelatin-slope growth, no liquefaction of gelatin, fermentation of glucose and lactose, acid production, milk clotting, neutral red reaction, indol production, - these can be separated into quite a number of varieties and, as far as I have re-tested their characters, stable varieties.

The following classification of organisms isolated has no significance other than practical convenience and the dulcitol fermentation might equally well be used as a group differentiator before saccharose.

Group I.-Saccharose fermenters. Sub-group (a) dulcitol fermented and sub-group (b) dulcitol not fermented. A large number of both sub-groups were met with. They could be further differentiated by their action on other substances. Thus some fermented salicin; others did not break up this substance. Some split up glycerine with gas production, others had no obvious action. So far all the bacilli coli of this group which fermented saccharose have fermented raffinose also. I have not found the converse true, however, since all raffinose fermenters do not also ferment saccharose.

Group II.-Dulcitol fermenters but not saccharose. Subgroup (a) raffinose fermented; and sub-group $(b)$ raffinose not fermented. A large number of organisms belonging to both sub-groups were isolated and could again be further differentiated by salicin and other substances.

Group III.-Maltose fermenters but not saccharose or dulcitol.

These have been rather less numerous than either Groups I. or II. in the results so far obtained. Most have fermented salicin but a few not. The majority have not fermented raffinose but a few have to a slight extent. In this way a very considerable differentiation into groups and subgroups can be made out but at present $I$ am not in a position to say whether there is any trustworthy differential distribution of these different sub-groups in excreta from different sources or any difference in their relative significance. That these differences exist indicates, however, the complexity of the subject.

Colchester.

\section{A CASE OF TYPHOID FEVER PRESENTING SOME UNUSUAL FEATURES.}

BY KENNETH ANDERSON, M.B. LOND, M.R.C.S. ENG., L.R.C.P. LOND.,

LATE HOUSE SURGEON, WESTON-SUPER-MARE HOSPITAL.

Arthougr the symptomatology of typhoid fever is notoriously subject to the greatest variations the following case seems to me to have an unusual share of atypical features and on that account may be of interest to the profession.

A woman, aged 30 years, was admitted into the Westonsuper-Mare Hospital on March 6th, 1903, for severe pain in the left loin. On March 1st she had had a "shivering fit" followed by pain. Previously to this she had felt quite well.

4 Since writing this paper in the early autumn a most valuable eontribution to the subject by Dr. A. C. Irouston has been publishert in the report of the medical officer to the Local Government Board, 1902-03. This should be consulted for a more complete description of the characters of bacillus coli from normal stools.
During the next few clays she was feverish and the pain was more or less continuous. She had noticed nothing unusual in her urine. Dr. G. H. 'Temple, who had been called in and found her surrounclings unsuitable, advised her removal to the hospital. She was admitted as a surgical case under the care of Dr. G. F. Rossiter. On admission the temperature was $101 \cdot 4^{\circ} \mathrm{F}$., the pulse was 104 , and the respirations were 26. The patient was not in actual pain. 'The abclomen was moving fairly well and was not distended; it was supple in most parts except in the left hypochondrium, which was rigid and extremely tender, and there was slight rigidity of the recti ; palpation in the left loin caused mucl pain and the skin over the region of the kidney was hyperzsthetic. The patient had been sick and was constipated; the tongue was clean but rather dry; a few sibilant rhonchi were heard over both upper lobes, more especially on the right side. The urine was acid and contained a small amount of pus; the patient afterwards told us that she had had cystitis two years ago. On the $8 \mathrm{th}_{1}$, at $10 \mathrm{P}$.M., the temperature was $103^{\circ} 2^{\circ}$; tenderness in the loin was less; the bowels were relieved by calomel. 'The temperature gradually fell during the next few days and the pain and tenderness in the loin entirely disappeared; the recti, however, remained rigid. 'There was now some impaired resonance at the left base, with slight harshness of the expiratory sound; rhonchi were still heard over the right upper lobe. The pulse was soft but not dicrotic and during this period of pyrexia never exceeded 100 after the 10th. The temperature oscillated irregularly from the 11th to the 15th and was normal on the evening of the latter day; the tonome was moister and the patient now felt fairly well. The only treatment adopted beyond purgatives was the application of turpentine fomentations to the abdomen. The case was regarded by Dr. Rossiter and also by Dr. K. Roxburgh, who was thenceforth in charge of it as a medical case, as one of perinephritic inflammation which had subsided. The question of renal tuberculosis was considered, but the specimen of urine submitted to the Clinical Research Association was free from tubercle bacilli.

The patient now seemed to be on the road to recovery; the temperature kept subnornal for four days; the diet was increased gradually, but on the evening of the fifth day of apyrexia (the 20th) the temperature suddenly rose to $1028^{\circ}$, a rub was heard at the right base, and an occasional crepitation in the lungs. The temperature became distinctly oscillating but seldom reached normal even in the mornings, and in the evenings was generally $102^{\circ}$ or $103^{\circ}$; the pulse kept about 100 and the respirations 24. A hæmorrhagic vaginal discharge, which was at first taken to be a menstrual period, began on March 21st, the period being a month overdue. From the 28th to the 31st the fever was much less and the patient seemed better; during this time there was no pain or abdominal tenderness but the recti were always rigid. 'Sibilant rhonchi persisted at the right apex but otherwise there were no definite physical signs pointing to pulmonary disease. The urine still contained a little pus. By the evening of the 31st the temperature was $101 \cdot 2^{\circ}$ it kept at this level next day, the pulse being 96 ; the tongue was dry and slightly furred. The patient was looking ill and rather lethargic. On April 2nd a report of Widal's reaction given by the patient's blood was received from the Clinical Research Association. The blood gave a good reaction with dilutions 1 in 10 and 1 in 25, and a slight reaction with dilution 1 in 50. There being no history of a previous attack of typhoid fever this was regarded as conclusive. That night her temperature reached $104 \cdot 8^{\circ}$; it fell quickly but at $4 \mathrm{\Lambda} . \mathrm{m}$. she had a rigor and the temperature being $104^{\circ}$ she was sponged with water at $80^{\circ}$. For the next four days the pyrexia continued without marked diurnal variations and she was twice sponged on the temperature reaching $103^{\circ}$. 'The pulse remained steady, about 96 to 100. She took milk well and enemata were given daily to relieve the bowels, the motions now being typically "peasoupy." The liver dulness reached an inch below the costal margin; the spleen could not be felt but the splenic dulness extended nearly to the nipple line; the recti muscles remained rigid. The vaginal discharge, which had continued since March 21st, now became very fou], and boric douches were given night and morning. On April 7th the temperature ranged a good deal lower, the maximum being $100 \cdot 2^{\circ}$. On the 8 th while micturating she passed, without pain, a small pear-shaped body per vaginam; this was very foul and consisted of a membranous bag containing fibrous tissue and blood clot and was considered to be 